\title{
The Medical Isotope Crisis: How We Got Here and Where We Are Going
}

\author{
Thomas J. Ruth
}

TRIUMF and the British Columbia Cancer Agency, Vancouver, British Columbia, Canada

\begin{abstract}
CE credit: For CE credit, you can access the test for this article, as well as additional JNMT CE tests, online at https://www.snmmilearningcenter.org. Complete the test online no later than December 2017. Your online test will be scored immediately. You may make 3 attempts to pass the test and must answer $80 \%$ of the questions correctly to receive $1.0 \mathrm{CEH}$ (Continuing Education Hour) credit. SNMMI members will have their CEH credit added to their VOICE transcript automatically; nonmembers will be able to print out a CE certificate upon successfully completing the test. The online test is free to SNMMI members; nonmembers must pay $\$ 15.00$ by credit card when logging onto the website to take the test.
\end{abstract}

\begin{abstract}
$99 \mathrm{~m} T \mathrm{c}$ is the most widely used radionuclide in nuclear medicine. The reactor stoppages that occurred in recent years illustrated the vulnerability of the availability of radiotracers for imaging. With many of the reactors due for shutdown over the next 5-10 y, alternative routes to producing the ${ }^{99} \mathrm{Mo} /{ }^{99 m T c}$ pair are being explored. This brief review examines how we have reached this situation and what the near and distant future holds for securing the availability of these radioisotopes.
\end{abstract}

Key Words: ${ }^{99} \mathrm{Mo}$; ${ }^{99 m T c}$; nuclear medicine; isotope production

J Nucl Med Technol 2014; 42:245-248

DOI: $10.2967 /$ jnmt.114.144642

$\mathbf{T}$ he most widely used radionuclide in nuclear medicine worldwide is ${ }^{99 \mathrm{~m}} \mathrm{Tc}$. Approximately $85 \%$ of all nuclear medicine scans use ${ }^{99 m} \mathrm{Tc}$. That amounts to 76,000 scans/d (>1 scan/s), or $20-40$ million doses/y (1-3). The ${ }^{99 \mathrm{~m}} \mathrm{Tc}$ derives from a generator containing ${ }^{99} \mathrm{Mo}$, which decays to ${ }^{99 \mathrm{~m}} \mathrm{Tc}$. The generator is made possible by the difference in half-lives between the two isotopes; ${ }^{99} \mathrm{Mo}$ has a 66 -h half-life, and ${ }^{99 \mathrm{~m}} \mathrm{Tc}$ decays with a half-life of $6 \mathrm{~h}$. The ${ }^{99 \mathrm{~m}} \mathrm{Tc}$ is a meta-stable state of ${ }^{99} \mathrm{Tc}$, meaning that its decay results in the ground state of ${ }^{99} \mathrm{Tc}$, which has a half-life of $220,000 \mathrm{y}$. With that long half-life, ${ }^{99} \mathrm{Tc}$ is difficult to detect even though it is technically radioactive.

The fission of ${ }^{235} \mathrm{U}$ provides ${ }^{99} \mathrm{Mo}$ in very high specific activity, typically greater than $185 \mathrm{TBq}(5,000 \mathrm{Ci}) / \mathrm{g}$. That means a $370-\mathrm{GBq}$ (10-Ci) generator would have $2 \mathrm{mg}$ on its column; an amount that is about the weight of a mosquito. With such a small mass on the column, the volume of saline to elute the nucleogenic ${ }^{99 \mathrm{~m}} \mathrm{Tc}$ can be relatively small, typically about $10 \mathrm{~mL}$ or less. The radiopharmaceutical kits

\footnotetext{
Received Jun. 20, 2014; revision accepted Oct. 6, 2014.

For correspondence or reprints contact: Thomas J. Ruth, TRIUMF, 4004

Wesbrook Mall, Vancouver, BC V6T 2A3, Canada.

E-mail: truth@triumf.ca

Published online Nov. 11, 2014.

COPYRIGHT (C 2014 by the Society of Nuclear Medicine and Molecular Imaging, Inc.
}

used to prepare the tracers for imaging have been optimized to work within these parameters.

Until about 2010, the supply was provided by 5 multipurpose research reactors owned and operated by their respective governments. The National Research Universal (NRU) Reactor in Canada and the High Flux Reactor in The Netherlands supplied approximately $70 \%$ of the world demand, and the remaining 3 reactors (Safari in South Africa, BR2 in Belgium, and Osiris in France) combined to make up the difference. All are more than 3 decades old, with two having been built over 50 y ago. Despite efforts by the respective teams to maintain the infrastructures, these oldest reactors have gone through a series of unanticipated interruptions associated with an aging infrastructure. There was a period when two were unavailable for ${ }^{99}$ Mo production for more than 6 mo and a period when at least one was not operational for more than a year (4).

These disruptions caused major shortages of ${ }^{99}$ Mo resulting in cancellation of many procedures, delay of diagnoses, or use of inferior procedures. Over the last few years, concern has grown about the reliability of the supply.

In addition to these disruptions, there is growing concern about the use of enriched ${ }^{235} \mathrm{U}$ as a target material for the production of ${ }^{99} \mathrm{Mo}$. Until 2010, all reactors used highly enriched uranium (HEU), with most using 93\% enriched uranium (Safari used 50\% enrichment). Enrichments greater than $19.7 \%$ are classified as HEU. HEU is bombgrade uranium, meaning that a few kilograms can be used to build a thermonuclear device.

Thus, the combination of an aging reactor fleet and the use of HEU for production of ${ }^{99}$ Mo have resulted in several efforts to provide alternative routes to production without HEU.

\section{SOLUTIONS TO ${ }^{99}$ MO SHORTAGE}

The alternative routes for ${ }^{99} \mathrm{Mo}$ production have made use of either reactors or accelerators. The following sections describe the various efforts, including the advantages and disadvantages. Fission of ${ }^{235} \mathrm{U}$ is the most efficient approach but generates large quantities of radioactive fission waste. 


\section{Reactors}

With the ${ }^{99}$ Mo production reactors reaching the end of their useful age, there have been many discussions about building replacement reactors. Probably the most dramatic example is the Multipurpose Applied Physics Lattice Experiment (MAPLE) in Canada.

In 1996, Nordion contracted Atomic Energy of Canada Limited to build two isotope production reactors, each of which would have the capacity to supply the entire world with ${ }^{99}$ Mo. With this announcement, all consideration of building additional reactors for isotope production essentially ceased. The MAPLE reactors were to be completed by 2000 . However, by 2002 they still had not been commissioned. Although the reactors had been completed and were operational, the Canadian Nuclear Safety Commission, the agency that regulates all Canadian nuclear facilities, would not license the MAPLE reactors to operate because the reactors had a positive reactivity coefficient. Under normal operation, as a reactor heats up, the coolant water heats up and becomes less dense and thus less efficient at thermalizing neutrons and the reactor slows down, a self-regulating process. With the positive reactivity coefficient, the reactor actually increases in power output. The Canadian Nuclear Safety Commission felt that this was outside the design specifications of the MAPLE reactors and would not allow them to operate. Although numerous attempts were made to rectify the situation, none proved satisfactory and the project was abruptly cancelled in 2008 .

The operators of the existing fleet of reactors used to produce ${ }^{99} \mathrm{Mo}$ are under growing pressure to convert their targets from HEU to low-enriched uranium (LEU). The conversion requires modifying the target itself and the subsequent chemistry. To have the same amount of ${ }^{235} U$ in the target mix, approximately 5 times the amount of uranium is required (HEU, 93\% ${ }^{235} \mathrm{U}$; LEU, $<20 \%{ }^{235} \mathrm{U}$ ).

The OPAL (Open Pool Australian Lightwater) reactor at the Australian Nuclear Science and Technology Organisation was built to operate with LEU targets. The other operators have all made commitments to convert over the next few years. The Safari reactor in South Africa has made the most progress. However, acceptance by the user communities, especially in Europe, has been slow. That said, the Food and Drug Administration in the United States has approved the use of ${ }^{99}$ Mo generators prepared with LEU.

The High Flux Reactor in The Netherlands is supposed to be replaced with the LEU-based Pallas reactor in 2016. However, construction of the reactor has not been started, and the project has not been finalized; thus Pallas probably will be available no earlier than 2022 .

The one glaring exception to conversion is the NRU in Chalk River, Canada. The Conservative Party government of Canada has indicated that the NRU will cease producing medical isotopes in 2016. This decision was probably made, in part, because of the philosophy of the government, which is opposed to government subsidies for private industry.
All existing ${ }^{99}$ Mo producers, having been built several decades ago, are government-owned facilities and have multiple missions. As government-run reactors they are not operated as commercial entities, and the multiuse makes it difficult to separate the costs per mission. Thus there is an inherent subsidy associated with the isotope programs.

Because the NRU represents approximately $40 \%$ of the supply, there is growing concern that further disruptions will occur during and after 2016 because of the fragility of the supply, especially if one of the remaining reactors goes down for some reason $(4,5)$.

\section{Other Options for Supply Replacement}

The National Nuclear Security Administration in the United States has been the agency tasked with overseeing the removal of HEU from civilian use, worldwide. In addition, the agency has funded several projects that have the mandate of producing ${ }^{99}$ Mo without the use of HEU to enable the United States to have a domestic supplier, thus reducing dependence on foreign suppliers.

The National Nuclear Security Administration has contracts with 4 entities, with 5 projects being under development (3).

GE-Hitachi proposed irradiating ${ }^{98} \mathrm{Mo}$ with neutrons from power-generating reactors. The produced ${ }^{99} \mathrm{Mo}$ would be of low specific activity because there is no simple chemical method for separating the two isotopes (98 and 99). The specific activity of the ${ }^{99} \mathrm{Mo}$ from neutron capture would be 37-370 GBq $(1-10 \mathrm{Ci}) / \mathrm{g}$, compared with the more than $185 \mathrm{TBq}(5,000 \mathrm{Ci}) / \mathrm{g}$ from fission. The $(\mathrm{n}, \gamma)$ approach has been used in the past, and there are methods in the literature for isolating the ${ }^{99 \mathrm{~m}} \mathrm{Tc}$ in a solution-type generator. However, this project is on hold because the proponents feel the economics for this method are not favorable at this time.

NorthStar is pursuing two approaches, one based on the $(\mathrm{n}, \gamma)$ reaction and the other on the $(\gamma, \mathrm{n})$ reaction, which will be discussed below. NorthStar will use the MURR (Missouri University Research Reactor) for the source of neutrons. MURR produced ${ }^{99} \mathrm{Mo}$ via this method more than 3 decades ago. The one drawback from this method is the fact that MURR operates with HEU fuel. The U.S. Congress has exempted MURR to allow NorthStar to continue its production of many research isotopes until a fuel is designed that can provide the flux required for NorthStar's research and production program, which is extensive. However, foreign entities see exemption as a contradiction to the National Nuclear Safety Administration's mission of removing HEU from civilian use.

Babcock and Wilcox proposed using a solution reactor in which the LEU fuel, in solution, would serve as the source for ${ }^{99} \mathrm{Mo}$. The generated ${ }^{99} \mathrm{Mo}$ would be extracted from the solution matrix periodically. This approach is relatively new and requires development for commercial-scale production. This project is also on hold awaiting a suitable business partner.

SHINE Medical Technologies/Morgridge Institute for Research, based in Wisconsin, has proposed using a solution reactor as well, but with the idea of generating the neutrons 
from a $(\mathrm{D}, \mathrm{T})$ accelerator and operating the reactor in a subcritical mode, meaning that the reactor stops when the accelerator is turned off. The reactor core solution would still be radioactive from the fission products. This project is still in the development stages because the accelerator requires very high fluxes of neutrons; development is required both because of the beam current from the deuteron accelerator and because of the challenges of the solution reactor described above $(6)$.

Both of the solution reactor approaches make use of ${ }^{235} \mathrm{U}$ fission, and thus the generated ${ }^{99}$ Mo would be suitable for the existing generator systems used by the manufacturers (Lantheus and Mallinckrodt in the United States).

\section{Accelerators}

Accelerators have been proposed as a possible source of ${ }^{99}$ Mo because they inherently have lower waste associated with their operation and they can be turned on and off with no major residual radiation associated with the facility. There are two basic approaches: making use of the inverse reaction to neutron capture-that is, bombarding a ${ }^{100} \mathrm{Mo}$ target with photons (the $(\gamma, \mathrm{n})$ reaction) - and directly producing ${ }^{99 \mathrm{~m}} \mathrm{Tc}$ via the proton bombardment of ${ }^{100} \mathrm{Mo}$ (4).

In the first of these two basic approaches, the photons are produced by an electron accelerator that generates a highintensity electron beam of around 35-50 MeV that then bombards a high " $z$ " material such as tungsten, called a converter. Deceleration within the converter produces a beam of photons called bremsstrahlung radiation. The photons are distributed over a wide energy range, peaking at the low-energy portion of the spectrum and decreasing fairly rapidly in intensity with increasing energy. To efficiently "knock out" a neutron, a photon of around $14 \mathrm{MeV}$ is needed. Thus, electron energy of $35-50 \mathrm{MeV}$ is chosen to provide photons that cover the energy region of 10-20 MeV with sufficient intensity. Just as with the (n, $\gamma)$ approach, the $(\gamma, n)$ product will be of low specific activity for the same reason (37-370 GBq [1-10 Ci]/g); the target and product are of the same element. Thus, the generator for extracting the ${ }^{99 \mathrm{~m}} \mathrm{Tc}$ must take this into account. Also, the target material is expensive because natural molybdenum contains only $10 \%$ ${ }^{100} \mathrm{Mo}$ and the target needs to have an enrichment of approximately $95 \%{ }^{100}$ Mo or greater in order to be efficient in production (6). NorthStar in the United States and the Prairie Isotope Production Enterprise in Canada are developing this approach. This approach is in the prototype stage.

The second of the two basic approaches uses the direct production of ${ }^{99 \mathrm{~m}} \mathrm{Tc}$ via proton irradiation of ${ }^{100} \mathrm{Mo}$, making use of the ${ }^{100} \mathrm{Mo}(\mathrm{p}, 2 \mathrm{n})^{99 \mathrm{~m}} \mathrm{Tc}$ reaction in cyclotrons. This approach was proposed in 1971 but because of the wide availability of ${ }^{99} \mathrm{Mo}$ from reactors it was not pursued further other than for the measurement of excitation functions (7). Two Canadian consortia are pursuing this approach (4). The first, based out of TRIUMF, is demonstrating that the beam current of existing cyclotrons designed to produce PET radionuclides can be upgraded to meet local needs for ${ }^{99 \mathrm{~m}} \mathrm{Tc}$.
The collaborators for this project include the British Columbia Cancer Agency (TR19 cyclotron), the Lawson Health Science Institute in London, Ontario, and the Centre for Probe Development in Hamilton, Ontario. Both of the Ontario centers have 16-MeV PETtrace cyclotrons. The second consortium, between the Edmonton Pharmaceutical Centre and the Université de Sherbooke, is using a new line of high-power cyclotrons operated at around $24 \mathrm{MeV}$ (TR24, Advanced Cyclotron Systems, Inc.).

The cyclotron approach is fairly advanced, well beyond the proof-of-principle stage. The approach uses cyclotrons with an energy range of between 14 and $24 \mathrm{MeV}$ at a relatively high beam current $(>100 \mu \mathrm{A})$. The targets require development to operate at greater than $100 \mu \mathrm{A}$, the higher the better. Recent results at $18 \mathrm{MeV}$ produced $350 \mathrm{GBq}(9.4 \mathrm{Ci})$ with a beam of $240 \mu \mathrm{A}$ for $6 \mathrm{~h}$. At $16.5 \mathrm{MeV}$ and $130 \mu \mathrm{A}$ for $3 \mathrm{~h}$, more than $17 \mathrm{GBq}(4.7 \mathrm{Ci})$ were produced (7).

The challenge in this approach is to make sufficient quantities at a purity that is high enough to prevent the patient from receiving an unduly increased radiation exposure from the ${ }^{99 \mathrm{~m}} \mathrm{Tc}$ dose. This challenge is due to the fact that the target material, ${ }^{100} \mathrm{Mo}$, must be of a sufficiently high enrichment to generate the desired ${ }^{99 \mathrm{~m}} \mathrm{Tc}$ while keeping the other technetium isotopes at a minimum. Because ${ }^{95} \mathrm{Tc}$ and ${ }^{96} \mathrm{Tc}$ have longer half-lives, their contribution grows with time. These contaminant technetium isotopes are generated from the small quantities of molybdenum isotopes present in the enriched ${ }^{100} \mathrm{Mo}$. Both the challenge of high yield and the challenge of high purity have been met, as well as recovery of the enriched target material (7).

The proponents of the cyclotron approach have demonstrated the labeling of the various radiopharmaceuticals using manufacturer's kit formulations, and all have passed the quality test. Preclinical scans have demonstrated, not surprisingly, that the cyclotron ${ }^{99 \mathrm{~m}} \mathrm{Tc}$ behaves in an identical manner to generator ${ }^{99 \mathrm{~m}} \mathrm{Tc}$. In a small clinical trial, the same results have been observed in human subjects $(8,9)$.

Although the cyclotron approach is being driven by the 2 collaborative programs, there is growing interest in this approach since it is showing promise and is the least expensive approach for producing ${ }^{99 \mathrm{~m}} \mathrm{Tc}$ on a local or regional basis. The increased interest is illustrated by the fact that the International Atomic Energy Agency has organized a coordinated project to fund research on the cyclotron approach. Eleven countries are participating in this effort (Armenia, Brazil, Canada, Hungary, Italy, Japan, Korea, Poland, Saudi Arabia, Syria, and the United States). The IAEA has assisted in installing cyclotrons in many of these countries for PET and sees this as an opportunity to increase the value of their investment.

\section{CONCLUSION}

One of the major goals for the Organization for Economic Co-operation and Development is to achieve ${ }^{99 \mathrm{~m}} \mathrm{Tc}$ pricing that is based on full cost recovery $(10,11)$. In principle, this should be doable for "greenfield" single-purpose facilities. 
However, in the short term at least the multipurpose reactors will still be providing ${ }^{99} \mathrm{Mo}$ in a complicated and highly subsidized environment. Without full cost recovery, the new approaches will have a difficult time penetrating the market. Since most of the approaches compete with the existing high-specific-activity generator, there is no incentive for the generator manufacturers to accept these alternatives as long as fission ${ }^{99} \mathrm{Mo}$ is available.

With less than $2 \mathrm{y}$ before the shutdown of the NRU reactor for isotope production in 2016, there are a few bright spots for keeping the supply of ${ }^{99} \mathrm{Mo}$ and ${ }^{99 \mathrm{~m}} \mathrm{Tc}$ stable. The existing infrastructure of large reactors will be upgraded to increase their production capacity, which should cover the short-term concerns. However, several of these reactors are reaching the end of their life span and will probably cease production by 2020 .

The NorthStar approaches aim to cover at least half the U.S. demand and, if successful, could scale up to cover the entire U.S. demand. In a similar fashion, the SHINE Medical Technologies approach could meet a significant portion of the U.S. demand for ${ }^{99} \mathrm{Mo}$ if the technologic challenges can be resolved. Canada will probably implement the cyclotron approach, since there are at least 10 cyclotrons that presently have that capacity or could be upgraded to have the requisite infrastructure, including a higher proton beam current. Canada would still require some generators for locations far from urban centers. Smaller countries with relatively low demand could meet their needs with as little as a single cyclotron.

Both accelerator approaches require enriched ${ }^{100} \mathrm{Mo}$, and at this time only Rosatom in Russia is supplying large quantities of ${ }^{100}$ Mo through its commercial partners around the world. Having a single supplier adds concern about a single point of failure. Newer reactors being proposed may ultimately be built, but the cost may make it difficult to have a viable business based on ${ }^{99} \mathrm{Mo}$ supply alone if the Organization for Economic Co-operation and Development is able create an economically fair environment. Although there is reason for optimism, the supply of ${ }^{99} \mathrm{Mo}$ and ${ }^{99 \mathrm{~m}} \mathrm{Tc}$ is fragile and will remain so for the remainder of this decade and perhaps beyond.

\section{DISCLOSURE}

The funding for the cyclotron projects has been provided by several grants from CIHR/NSERC and Natural Resources
Canada. No other potential conflict of interest relevant to this article was reported.

\section{ACKNOWLEDGMENTS}

I wish to thank the many people with whom I have interacted over the last half dozen or more years in discussing this important topic for the medical community. In particular, the assistance and leadership provided by Drs. Francois Benard, Paul Schaffer, and Ken Buckley has made these last few years exciting and fruitful, as have the efforts of the entire Cyclotech99 team. Discussions with the panel members on multiple committees reviewing the status of ${ }^{99} \mathrm{Mo}$ availability at the IAEA, the National Academy of Sciences, and the Department of Energy has been enlightening, especially with Drs. Kevin Crowley and Chris Whipple. The sharing of slides describing the various approaches by the presenters at multiple conferences illustrates the generosity of our community.

\section{REFERENCES}

1. Ruth T. Accelerating production of medical isotopes. Nature. 2009;457:536-537.

2. Pillai MR, Dash A, Knapp FF Jr. Sustained availability of ${ }^{99 \mathrm{~m}} \mathrm{Tc}$ : possible paths forward. J Nucl Med. 2013;54:313-323.

3. Loukianova A. What the doctor ordered: eliminating weapons-grade uranium from medical isotope production. NTI website. http://www.nti.org/analysis/ articles/what-doctor-ordered-eliminating-weapons-grade-uranium-medical-isotopeproduction. Published September 5, 2012. Accessed October 8, 2014.

4. Whipple C, Larson SM, Atkins-Duffin C, et al. The Production of Medical Isotopes Without HEU. Washington, DC: National Academy Press; 2009.

5. Government of Canada Response to the Report of the Expert Review Panel on Medical Isotope Production. Natural Resources Canada website. https://www. nrcan.gc.ca/sites/www.nrcan.gc.ca/files/energy/pdf/eneene/sources/uranuc/pdf/ isotopes-gc-re-eng.pdf. Published March 30, 2010. Accessed October 8, 2014.

6. Non-HEU Production Technologies for Molybdenum-99 and Technetium-99m. Vienna, Austria: International Atomic Energy Agency; 2013. Nuclear Energy Series NF-T-5.4.

7. Beaver JE, Hupf HB. Production of ${ }^{99 \mathrm{~m}} \mathrm{Tc}$ on a medical cyclotron: a feasibility study. J Nucl Med. 1971;12:739-741.

8. Bénard F, Buckley KR, Ruth TJ, et al. Implementation of multi-curie production of ${ }^{99 \mathrm{~m}} \mathrm{Tc}$ by conventional medical cyclotrons. J Nucl Med. 2014;55:1017-1022.

9. McEwan A, McQuarrie S, Abrams D, et al. Technetium-99m (Tc-99m) pertechnetate ( $\mathrm{TcO} 4)$ imaging with cyclotron produced $\mathrm{Tc}-99 \mathrm{~m}$ compared with generator Tc-99m [abstract]. J Nucl Med. 2012;53(suppl 1):321P.

10. The supply of medical radioisotopes: the path to reliability. Nuclear Energy Agency website. https://www.oecd-nea.org/med-radio/reports/med-radio-reliability. pdf. Published 2011. Accessed October 15, 2014.

11. The supply of medical radioisotopes: market impacts of converting to lowenriched uranium targets for medical isotope production. Nuclear Energy Agency website. http://www.oecd-nea.org/ndd/reports/2012/7129-leu.pdf. Published 2012. Accessed October 8, 2014. 